
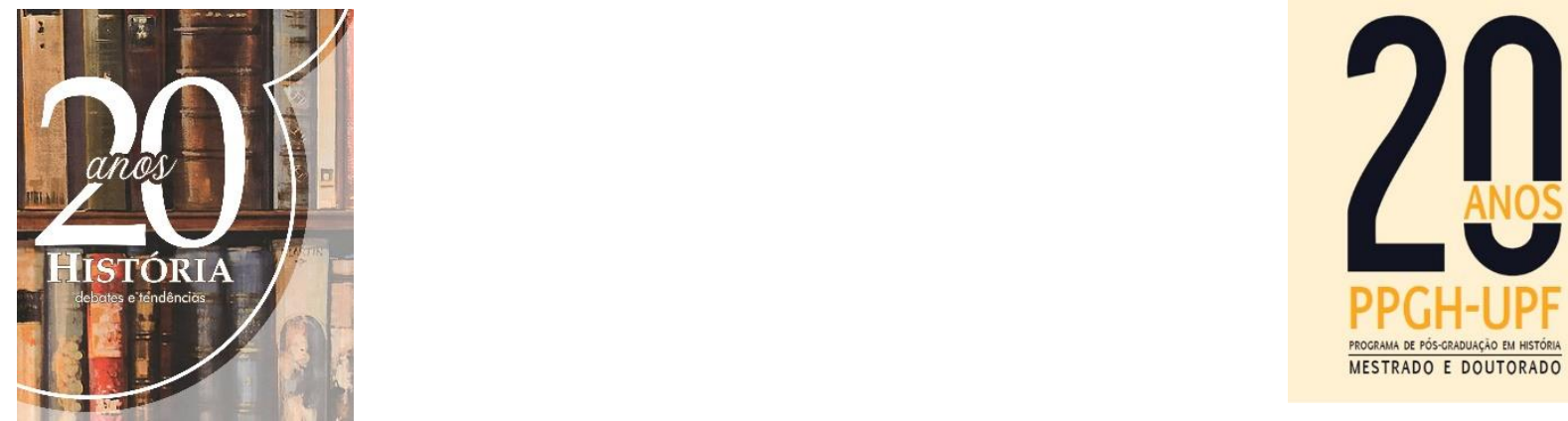

\title{
Modos de pertencimento, fontes de guerra: nacionalismo e identidade religiosa nos séculos XX e XXI
}

\author{
Modes of belonging, sources of war: nationalism and religious identity in the
}

\author{
twentieth and twenty-first centuries
}

\section{Modos de pertenencia, fuentes de guerra: nacionalismo e identidad religiosa en los siglos XX y XXI.}

Tatiana Vargas Maia ${ }^{i_{i}}$

\begin{abstract}
Resumo: O propósito deste artigo é mapear os pontos de semelhança existentes entre identidades religiosas e identidades nacionais, identificando algumas vias de acesso que permitam articular uma reflexão a respeito da relação entre os efeitos da politização de identidades religiosas e nacionalistas e as nossas formas de conflito e guerra. Inicialmente, apresento os conceitos fundamentais de nacionalismo e religião, conforme estabelecidos na literatura da História e das Ciências Sociais. Na sequência, relaciono as noções de identidade nacional e identidade religiosa com a incidência de conflitos violentos, explorando como esses padrões de pertencimento político e social específicos podem servir como combustível para a incidência de violência política.
\end{abstract}

Palavras-chave: Guerra. Identidade Religiosa. Nacionalismo.

\begin{abstract}
The purpose of this paper is to map the similarity points between religious identities and national identities, identifying some lines of access that allow us to articulate a reflection on the relationship between the effects of the politicization of religious and nationalist identities and our forms of conflict and war. Initially, I present the fundamental concepts of nationalism and religion, as established in the history and social sciences literature. Next, I relate the notions of national identity and religious identity to the incidence of violent conflict, exploring how these specific patterns of political and social belonging can serve as fuel for the incidence of political violence.
\end{abstract}

Keywords: Nationalism. Religious Identity. War.

Resumen: El propósito de este artículo es mapear los puntos de similitud entre las identidades religiosas y las identidades nacionales, identificando algunas formas de acceso que nos permitan articular una reflexión sobre la relación entre los efectos de la politización de las identidades religiosas y nacionalistas y nuestras formas de conflicto y guerra. Inicialmente, presento los conceptos fundamentales del nacionalismo y religión, según lo establecido en la literatura de Historia y Ciencias Sociales. Luego, relaciono las nociones de identidad nacional y identidad religiosa con la incidencia de conflictos violentos, explorando cómo estos patrones específicos de pertenencia política y social pueden servir como combustible para la incidencia de violencia política.

Palabras clave: Guerra. Identidad religiosa. Nacionalismo. 


\section{Introdução}

As políticas de identidade talvez sejam a grande característica da política contemporânea. A noção de uma política de identidade "sugere uma orientação política construída ao redor de uma identidade social (pré-existente)" (FORD, 2005, p. 53-57), ou seja, quando discutimos identidades políticas o nosso foco se dirige para os interesses e as perspectivas de grupos formados pelo compartilhamento de características específicas, tais como nacionalidade, religião, etnia, ou gênero. Pensando na história contemporânea, desde o seu marco cronológico inicial da Revolução Francesa, em 1789, uma forma específica de identidade se estabeleceu como força motriz de movimentos políticos relevantes: o nacionalismo. Podemos destacar a própria Revolução Francesa, a Primavera dos Povos, a Primeira e a Segunda Guerra Mundial como momentos de definição de dinâmicas políticas internacionais que foram decisivamente moldados por nacionalismos. Todavia, se tradicionalmente a investigação acerca de políticas de identidade se centrou no estudo de nacionalismos, uma observadora atenta não deve ignorar também a influência que uma outra forma de identidade - a religiosa - possui sobre as dinâmicas políticas dos séculos XX e XXI, sobretudo. Ao comparar ambas as formas de pertencimento social é inevitável perceber as similaridades que essas identidades - esses modos de pertencimento - compartilham, de maneira que, se nos parece intuitivo pensar em guerras e religiões, é igualmente evidente pensar em guerras e nacionalismos. E, para aqueles de nós que viveram a década de 1990, é possível adicionar: é igualmente óbvio pensar em guerras, religiões e nacionalismos. A Bósnia, na desesperadora figura de Slobodan Milosevic, não nos permite esquecer a potencial e a trágica interação entre essas variáveis.

O propósito deste artigo é apontar alguns pontos de semelhança e certos pontos de acesso que possibilitem uma reflexão a respeito da relação entre os fenômenos religiosos e os nacionalistas - um ancestral e o outro contemporâneo -, bem como sublinhar de que modo um melhor entendimento das dinâmicas religiosas e nacionalistas informa as nossas práticas políticas e consequentemente, de acordo com Clausewitz (1989, p. 87), as nossas formas de guerra. Inicialmente, apresento os conceitos fundamentais de nacionalismo e religião, conforme estabelecidos na literatura das ciências sociais, com destaque para as ideias de "comunidades imaginadas", desenvolvida por Benedict Anderson (1991), e "povos escolhidos", conforme definida por Peter van der Veer e Hartmut Lehmann (1999). Na sequência, relaciono as noções de nacionalismo e religião com a incidência de conflitos violentos, explorando como essas 
identidades específicas podem servir como combustível para a incidência de violência política.

\section{Algumas definições iniciais}

Antes de traçar os paralelos entre religião e nacionalismo, bem como as consequências que os mesmos podem ter sobre formas de violência política, cabem aqui alguns esclarecimentos conceituais. A minha opção para esse artigo foi focar em conceitualizações relativamente abrangentes, que, ao meu ver, articulam estruturalmente bem as realidades e as consequências sociais do nacionalismo e da religião.

É impossível falar de nacionalismo sem falar de nação. Steven Grosby (2005, p. 14) define a nação como "uma comunidade de parentesco, especificamente, uma comunidade de natividade que é limitada, territorialmente extensa, e temporalmente profunda" (2005, p. 14). O nacionalismo, conforme define Hobsbawn (1992, p. 4), é o programa político da nação, e como tal, avança orientações muito específicas para ação política - seja para os grupos nacionais menores ou para os estados nacionais estabelecidos. Portanto, o nacionalismo não apenas define a nação em termos de quem são os seus membros, quais são os seus valores e as suas relações com outros países, mas também incorpora um grupo com orientação política específica (CITRIN et al, 1994, p. 2). Nacionalismo, nesse sentido, é o sentimento de lealdade e de pertencimento a essa comunidade, é um sentimento de grupo compartilhado que ressalta a relevância de uma região geográfica e às vezes demográfica, e que busca, sobretudo, a independência desse grupo, geralmente definido em termos culturais ou étnicos. Tal sentimento mantém esse grupo unido, e pode ser expresso como uma crença ou uma ideologia política que conduz a identificação profunda de um indivíduo com uma nação. Nacionalismo, como essa definição deixa evidente, condiciona uma visão de mundo bastante específica e orienta a ação política.

O conceito clássico de Clifford Geertz (1989, p. 104-105) define religião como

(1) um sistema de símbolos que atua para (2) estabelecer poderosas, penetrantes e duradouras disposições e motivações nos homens através da (3) formulação de conceitos de uma ordem de existência geral e (4) vestindo essas concepções com tal aura de fatualidade que (5) as disposições e motivações parecem singularmente realistas" (1989, p. 104-105).

Se aceitarmos essa definição, admitimos que religião é outro fenômeno que poderosamente articula uma visão de mundo específica e que também pode orientar - e geralmente orienta - para uma ação de cunho político. Não coincidentemente, E. Renan, em seu 
célebre ensaio $O$ que é uma nação?, define nação como "uma alma, um princípio espiritual" (RENAN, 1992). Nacionalismos e religiões, de maneira geral, têm a pretensão de instituir um ethos definido, ou seja, modos de ser e posturas de orientação amplas no mundo que sintetizem um grupo particular.

Essa aproximação se torna especialmente clara quando utilizamos o conceito de “comunidades imaginadas", de Benedict Anderson, que será discutido na próxima subdivisão deste texto, como chave de leitura para ambas realidades de pertencimento nacional e religioso.

\section{Comunidades religiosas, comunidades nacionais: comunidades imaginadas}

Em seu livro Comunidades imaginadas, publicado originalmente em 1983, Anderson define "nação" como uma comunidade política imaginada, que é imaginada como sendo inerentemente limitada e soberana. Imaginada porque nem mesmo os membros das nações mais minúsculas jamais conhecerão, encontrarão ou nem sequer ouvirão falar de todos os seus companheiros (compatriotas), embora todos tenham em mente a imagem viva da comunhão entre eles. Ela é limitada porque até mesmo a maior delas, que agregue, por exemplo, um bilhão de habitantes, possui fronteiras finitas ainda que elásticas. Nenhuma delas imagina ter a mesma extensão da humanidade. Por fim, ela é soberana porque a única maneira de serem livres é serem soberanas sobre um pedaço determinado de terra. E uma nação é uma comunidade que, independente da desigualdade e da exploração que possam existir dentro dela, a nação sempre é concebida como uma profunda camaradagem horizontal (ANDERSON, 1991, p. 6-7).

Tomando essa especificação do conceito de nações comunidades imaginadas, não parece exagerado ou fora de propósito afirmar que esse conceito também pode ser utilizado como chave de leitura para a religião, ou pelo menos para mostras empíricas do fenômeno religioso, sobretudo em suas manifestações mais contemporâneas. Religiões também constituem grupos imaginados, no sentido de que nenhum de seus membros algum dia conseguirão conhecer os seus correligionários; são grupos limitados, tendo em vista que, apesar da ambição de universalismo de diversas religiões (como o cristianismo e o islamismo, por exemplo), as suas fronteiras são finitas (e essas fronteiras podem ser concebidas tanto em termos territoriais - no caso de estados que adotam uma religião oficial - quanto populacionais, entendendo-se a totalidade de fiéis e adeptos ao redor do mundo); é soberana, ainda que não territorialmente. Constitutivamente, as religiões se imaginam enquanto doutrinas soberanas na definição dos padrões de comportamento e das atitudes de seus adeptos. Por fim, também 
buscam estabelecer um senso de camaradagem horizontal entre os seus fiéis (Ainda assim, é importante sublinhar: a análise de nações ou religiões como construções sociais não reduz a sua eficiência na vida cotidiana. Pelo contrário, como alguns dos exemplos recentes testemunham, tanto o nacionalismo como a religião são forças sociais e políticas extremamente influentes no mundo contemporâneo).

Ademais, outras três características não apenas conectam, mas clarificam e expandem as interações entre religião e nacionalismo exploradas acima (especialmente aquelas de cunho mais racialista). A noção de "povo escolhido", bastante comum na retórica religiosa, se aproxima bastante de algumas definições de nação e nacionalismo. Como Van Der Veer e Lehmann (1999, p. 6-7) destacam:

Três conceitos relacionados desenvolvidos por pensadores do século XIX merecem atenção especial na compreensão da interação entre elementos religiosos, nacionalismo e a noção de raça ou de qualidades raciais especiais. Primeiramente, a ideia da escolha de um determinado povo, que envolve e incorpora ingredientes políticos, sociais e religiosos. Em segundo lugar, o tema do renascimento de toda uma nação. [...] A terceira ideia estava intimamente conectada com essas duas pressuposições. No contexto das noções de escolha e de renascimento nacional, nós também podemos encontrar a crença em um novo messias, ou seja, a crença em um salvador que é supostamente chamado por Deus e que vem com o propósito de ressuscitar todo um povo (1999, p. 6-7).

Assim, ambas categorias compartilham a noção da escolha de um certo povo, o que incorpora claros elementos políticos e sociais. Em segundo lugar, temos frequentemente presente, em manifestações religiosas ou nacionalistas, o tema do renascimento ou da renovação de uma nação. Por fim, e conectando essas duas características anteriores, temos a relevância da figura de um messias, ou seja, um salvador - convocado por Deus ou pelo ethos nacional -, que surge para ressuscitar todo um povo (aqui, os paralelos com a Alemanha hitlerista não precisam de mais do que uma menção an passant para fazer sentido nessa esquematização). $\mathrm{O}$ mais importante é sublinhar que todas essas três marcas - a da escolha, a do renascimento e a do líder salvador - são essenciais para a articulação dessas comunidades, nacionais ou religiosas, em práticas políticas que possuem pretensões revisionistas (ou seja, de não aceitação do status quo e de tentativa de mudança do mesmo) e consequências transformadoras para o panorama político e social dos séculos XX e XXI.

Em uma linha de raciocínio parecida com a desenvolvida neste artigo, autores como Anthony Smith (1991, 2003), Rogers Brubaker (2015) e Elie Kedourie (1960) aprofundaram as aproximações entre o fenômeno religioso e o fenômeno nacionalista. Para Smith (2003, p. 4-5), o nacionalismo, ainda que constituído enquanto um sistema de crenças moderno, obtém e extrai diversas pressuposições de sistemas religiosos, como crenças em símbolos e rituais, apresentando-se praticamente como uma "nova religião". Burbaker (2015), por sua vez, 
considera nacionalismo e religião como fenômenos análogos: como modos de identificação, modos de organização social e como estratégias de enquadrar reinvindicações políticas. Para ele, ambos os fenômenos (1) possibilitam que indivíduos e grupos se situem em relação a outros, através da constituição de relações de semelhança e diferença; (2) podem ser entendidos como modos de organização social, uma vez que enquadram, canalizam e organizam relações sociais; e (3) demandas políticas de cunho religioso ou nacionalista são particularmente semelhantes, no sentido de que representam demandas de grupos particulares por recursos econômicos, representação política, reconhecimento simbólico ou reprodução cultural. Kedourie (1960, p. 55) sublinha as similaridades estruturais entre ambos os fenômenos, qualificando o nacionalismo como uma forma de religião moderna: ao invés de escolher símbolos, líderes e tradições religiosas como sagradas e veneradas, grupos nacionalistas adoram líderes, símbolos e tradições nacionais.

\section{Guerra, religião e nacionalismo}

Dessa forma, espero que já esteja claro como nacionalismo e religião não são apenas fenômenos sociais e políticos bastante similares; na última parte do estudo, meu objetivo é o de explorar como também eles (infelizmente, de maneira frequente) informam e alimentam dinâmicas de guerra e de violência política.

A ideia de que o nacionalismo é uma fonte de guerra não é nova: diversos estudos já investigaram como essa ideologia pode ser instrumental na mobilização para o conflito. Para Schrock-Jacobson (2012, p. 825), o “nacionalismo cria 'inimigos nacionais' com os seus aliados estrangeiros, gera pressupostos estratégicos que são tendenciosos, cria grupos de interesse nacionais que favorecem a guerra e permite a supressão de grupos de oposição [...] o nacionalismo aumenta a probabilidade de início de guerra" (2012, p. 825).

Van Evera (1994, p. 8), por sua vez, elenca algumas hipóteses bastante plausíveis sobre nacionalismo e guerra. Para ele, (1) quanto maior o número de nacionalidades irredentistas (ou seja, que buscam autonomia e independência através da separação territorial de seu Estado original), maior o risco de guerra; (2) quanto maior for o número de nacionalidades que buscam a recuperação de diásporas, sobretudo através do uso de estratégias de anexação, maior o risco de guerra; (3) quanto maiores forem os objetivos hegemonistas que as nacionalidades buscam umas em relação às outras, maior o risco de guerra; e, (4) quanto maior for o número de nacionalidades oprimidas, maior o risco de guerra. 
Boa parte dos argumentos expostos acima se baseia na lógica de inclusão/exclusão que é típica de movimentos nacionalistas, ou seja, da criação de grupos (ou comunidades imaginadas, para retomar o conceito exposto anteriormente) que se veem destinados a obtenção, manutenção e consolidação dos objetivos de identidade, unidade e autonomia (SMITH, 1991, p. 73). Todavia, sobretudo nos séculos XX e XXI, dado, por um lado, o caráter heterogêneo das populações de diversas regiões geográficas, e por outro o progressivo alargamento das nossas unidades políticas que administram esses territórios - os Estados (um processo que Charles Tilly (1996) descreve magistralmente em seu livro Coerção, Capital e Estados Europeus) -, esses objetivos têm se tornado cada vez mais complexos e engendrado cada vez mais conflitos.

Além disso, é interessante notar que a lógica desses argumentos não é estranha a movimentos e grupos religiosos. Excluída a identificação territorial (com algumas importantes ressalvas), diversas religiões buscam exatamente esses mesmos fins: unidade, identidade e autonomia. Não é à toa que um dos conflitos mais salientes hoje em dia, mesmo em Estados ocidentais que muitas vezes apressadamente e enganosamente julgamos livres de tensões religiosas, é o problema da liberdade de expressão religiosa - o caso Kim Davis, nos Estados Unidos, ilustra bem essa tensão (LOPES, 2015). Se a violência política é vista como um meio para a obtenção de tais fins por grupos nacionalistas, parece-me justo - e até óbvio - afirmar que não é estranho observar grupos religiosos empregando estratégias similares para a obtenção de fins semelhantes.

Por fim, após o destaque das semelhanças e aproximações entre religião e nacionalismo, parece-me justo perguntar: o que separa esses dois tipos de identidades políticas e de manifestações sociais? De maneira analítica, observando ambos os fenômenos enquanto visões de mundo que são motivadoras para a ação social, parece-me que a resposta é: pouco. Muitos investigadores inclusive doam ao nacionalismo a alcunha de "a religião do Estado" - e esse parece marcadamente ser o caso do fascismo italiano, expresso claramente na afirmaçãode Benito Mussolini n'A Doutrina do Fascismo (2006), por exemplo - “Tudo no Estado, nada contra o Estado e nada fora do Estado". Justamente por causa disso, autores como Juergensmeyer apontam para uma possível competição entre ambas as visões de mundo (sobretudo quando discutindo um nacionalismo secular), o que, em contextos específicos, pode ser encarado como mais uma possível fonte de tensão. Como são ideologias da mesma ordem, Juergensmeyer (1994, p. 33) sublinha que elas se constituem como rivais em potencial - ambas clamam a garantia da ordem e da autoridade sobre a sociedade, e por isso mesmo estabelecem uma dinâmica de competição.

De qualquer maneira, essa similaridade competitiva sugere apenas que algumas das 
dinâmicas apontadas neste estudo encontram uma validação empírica: essas ideologias totais, que articulam uma visão de um mundo dividido em grupos distintos e muitas vezes não conciliáveis, que por sua vez possuem objetivos de autonomia (e por vezes de supremacia), define um cenário de alto potencial belicoso. Ainda de acordo com Jurgensmeyer (1994, p. 33), "a linguagem de ambas contém imagens de grave desordem, bem como de ordem tranquila, e nisso elas trabalham para manter a esperança de que, apesar das aparências em contrário, por fim a ordem acabará por triunfar e a desordem será contida” (1994, p. 33).

\section{Nacionalismos religiosos e a potencialização de conflitos violentos}

Antes de encaminhar o ensaio para uma conclusão, parece-me importante sublinhar o fenômeno do nacionalismo religioso, que, ao unir essas duas formas de comunidade, esses dois modos de pertencimento, parece potencializar e radicalizar a disposição para o conflito de ambos os fenômenos.

Barbara-Ann Rieffer (2003, p. 225) define o nacionalismo religioso como a fusão entre os fenômenos do nacionalismo e da religião de modo que esses se tornam inseparáveis. Para essa autora, instâncias de nacionalismo religioso são aquelas nas quais “[...] as pessoas não apenas demandam a sua própria nação e soberania, mas reivindicam que a sua nação é baseada em uma religião. Elas desejam autonomia $e$ reconhecimento da sua religião" (2003, p. 225). Posto de outro modo, nacionalismo religioso representa a relação entre um sentimento nacionalista específico e uma crença religiosa particular, uma relação que resulta em uma politização do sentimento religioso e em uma forte influência de dogmas religiosos nas dinâmicas políticas. Philip Barker (2009, p. 13) especifica a definição de Rieffer sublinhando que, para considerarmos um movimento nacionalista como tendo um caráter religioso, "a religião deve ser central na identidade nacional e para as concepções do que significa pertencer a tal nação. Se a religião não for a característica central da identidade nacional, deve pelo menos ser uma dentre as características centrais" (2009, p. 13). Nesse sentido, o nacionalismo religioso constitui uma forma específica e um tipo distinto de nacionalismo (BRUBAKER, 2015). Roger Friedland (2002, p. 387) apoia essa interpretação, ao estabelecer o nacionalismo como uma forma (ou fórmula) que une estado, território e cultura, mas que pode ter o seu conteúdo variado. No caso do nacionalismo religioso, a religião fornece o conteúdo para essa fórmula, ou seja, as práticas discursivas que fornecem uma justificativa específica para a união de um estado com um território e uma cultura: 
A religião oferece uma maneira institucionalmente específica para organizar esta forma moderna de representação coletiva [nacionalismo], como uma coletividade representa-se a si mesma os símbolos, signos e práticas através dos quais ela se reconhece. A religião não muda a forma nacionalista de representação coletiva, apenas o seu conteúdo, privilegiando uma base de identidade e um critério de juízo que não pode não ser escolhido. $\mathrm{O}$ critério de julgamento religioso como os direitos humanos, a pureza racial ou a racionalidade técnica - está fora do alcance da voz popular ou dos interesses convincentes do Estado (2002, p. 387).

Essas definições convergentes de nacionalismo religioso são especialmente relevantes para o tópico em discussão nesse artigo: se anteriormente definimos tanto os nacionalismos quanto a religiões como fenômenos com um grande potencial de iniciar e alimentar conflitos violentos, devido ao seu caráter muitas vezes exclusivista e anti-universalista, e acentuamos a sua capacidade de articular antagonismos políticos bastante marcados, devido à definição e propagação de visões de mundo bastante específicas e concorrentes, parece justo compreender o nacionalismo religioso como um "barril de pólvora" político, que, muitas vezes, converte-se em movimentos fundamentalistas profundamente problemáticos. Nesse sentido, é bastante interessante contemplar alguns dos principais focos de conflito violento da política internacional contemporânea, que, não coincidentemente, parecem estar estrategicamente localizados em estados dominados por nacionalismos de cunho religioso (podemos pensar no conflito entre Israel e a Palestina, por exemplo, que envolve um caso clássico de nacionalismo religioso, bem como na tensão histórica existente entre Índia e Paquistão, ou até mesmo considerar o que essa discussão poderia contribuir para o nosso entendimento do Estado Islâmico do Iraque e do Levante - EIIL).

\section{Considerações Finais}

Tomando em consideração os pontos expostos anteriormente, parece-me que a sugestão central avançada no início desse artigo permanece válida: na medida em que são visões de mundo totalizantes, tanto a religião quanto o nacionalismo fornecem um substrato poderoso para a guerra. Quando unificadas, como é o caso do nacionalismo religioso, esse fundamento parece ainda mais potencializado. A história contemporânea, em toda a sua dimensão trágica, serve como testemunho disso.

Esse texto possui um caráter eminentemente ensaístico e teórico, no sentido em que tentei avançar nessas páginas algumas hipóteses a respeito da relação entre nacionalismo, religião e guerra, bem como conectar algumas leituras específicas acerca desses três fenômenos, que pudessem embasar uma consideração fundamentada dessa relação. Dessa forma, o presente 
artigo está longe de exaurir esse tema. Ainda que as literaturas sobre nacionalismo, religião e guerra sejam extensas, sobretudo na História e nas Ciências Sociais, é nítido que ainda há um extenso campo para a exploração da relação entre esses fenômenos, sobretudo na forma de estudos empíricos. É principalmente marcante a necessidade de consideração do fenômeno do nacionalismo religioso - tanto teórica quanto empiricamente -, que, apesar de pouco explorado academicamente, tem se demonstrado absolutamente presente e relevante na política contemporânea.

\section{Referências}

ANDERSON, Benedict. Imagined Communities: Reflections on the Origin and Spread of Nationalism. New York: Verso, 1991.

BAKER, Philip. Religious Nationalism in Modern Europe: If God Be for Us. London: Routledge, 2009.

BRUBAKER, Rogers. Grounds for Difference. Cambridge: Harvard University Press, 2015.

CITRIN, Jack et al. Is American nationalism changing? Implications for foreign policy. International Studies Quarterly, v. 38, n. 1, p. 1-31, 1994.

CLAUSEWITZ, Carl. On War. Princeton: Princeton University Press, 1989.

FORD, Richard Thompson. Political Identity as Identity Politics. Harvard Unbound, v. 1, n. 1, p. 53-57, 2005.

FRIEDLAND, Roger. Money, sex, and god: The erotic logic of religious nationalism. Sociological theory, v. 20, n. 3, p. 381-425, 2002.

GEERTZ, Clifford. A Interpretação das Culturas. Rio de Janeiro: LTC, 1989.

GROSBY, Steven. Nationalism: A Very Short Introduction. Oxford: Oxford University Press, 2005.

HOBSBAWM, Eric. Ethnicity and Nationalism in Europe Today. Anthropology Today, 8:1 (1992).

JUERGENSMEYER, Mark. The New Cold War: Religious Nationalism Confronts the Secular State. Berkeley: University of California Press, 1994.

KEDOURIE, Ellie. Nationalism. Londres: Hutchinson University Library, 1960. 
LOPES, German. Kentucky Clerk Kim Davis, Explained. Vox, 25 de setembro de 2015. Disponível in: http://www.vox.com/2015/9/1/9239011/kim-davis-gay-marriage. Acessado em: 17 de janeiro de 2016.

MUSSOLINI, Benito. The Doctrine of Fascism (1932). New York: Howard Fertig, 2006.

RENAN, Ernst. What is a Nation? Qu'est-ce qu'une nation? Paris: Presses-Pocket, 1992, translated by Ethan Rundell. Disponível http://ucparis.fr/files/9313/6549/9943/What_is_a_Nation.pdf. Acessado em: 17 de janeiro de 2016.

RIEFFER, Barbara-Ann J. Religion and nationalism: Understanding the consequences of a complex relationship. Ethnicities, v. 3, n. 2, p. 215-242, 2003.

SCHROCK-JACOBSON, Gretchen. The violent consequences of the nation: Nationalism and the initiation of interstate war. Journal of Conflict Resolution, v. 56, n. 5, p. 825-852, 2012.

SMITH, Anthony. National Identity. London: Penguin Books, 1991.

SMITH, Anthony. Chosen Peoples: Sacred Sources of National Identity. Oxford: Oxford University Press, 2003.

TILLY, Charles. Coerção, capital e Estados europeus 1990-1992. São Paulo: Edusp, 1996.

VAN DER VEER, PETER e LEHMANN, Hartmut. Nation and Religion: Perspectives on Europe and Asia. Princeton: Princeton University Press, 1999.

VAN EVERA, Stephen. Hypotheses on nationalism and war. International security, v. 18, n. 4, p. 5-39, 1994.

Submetido em: 26/10/2019

Aprovado em: 03/12/2019

Publicado: 23/12/2019

\section{Notas}

\footnotetext{
' Doutora em Ciência Política pela Southern Illinois University - Carbondale (2015). Atualmente, é coordenadora e professora do Bacharelado em Relações Internacionais, coordenadora e professora da Licenciatura e do Bacharelado em História da Universidade La Salle, professora permanente no Programa de Pós-Graduação em Memórias Sociais e Bens Culturais da Universidade La Salle. E-mail: vargasmaia@ gmail.com
} 